\title{
Typological diversity in New Englishes ${ }^{1}$
}

\author{
(pre-print version of paper in English World-Wide 30:2; \\ please email me atd.sharma@qmul.ac.uk for a copy of the published version)
}

\section{Devyani Sharma}

Queen Mary, University of London

Recent research has aimed to integrate the investigation of vernacular universals in native English dialects with variation in postcolonial varieties of English and cross-linguistic typology (Chambers 2004; Kortmann 2004). This article assumes that any search for universals in bilingual varieties must include an assessment of the grammatical conditioning of features and a comparison with the relevant substrates. Comparing Indian English and Singapore English, I examine three proposed candidates for English universals (Kortmann and Szmrecsanyi 2004), all of which show some presence in the two varieties - past tense omission, over-extension of the progressive, and copula omission. Past tense omission is found to be genuinely similar in the two varieties and accounted for by typological parallels in the substrates, whereas progressive morphology use and copula omission are found to be divergent in the two varieties and accounted for by typological differences in the substrates. All three variable systems are explicable as substrate-superstrate interactions, tempering claims of universality in both distribution and explanation.

Keywords: Indian English, Singapore English, typology, past, progressive, perfective, imperfective, copula, language transfer, universals

\footnotetext{
${ }^{1}$ I would like to thank Ashwini Deo and John Rickford for earlier collaborations that informed this work. I am also grateful to Lisa Lim, E-Ching Ng, Stephen Matthews, and Umberto Ansaldo for many helpful suggestions relating to the Singaporean situation, and E-Ching Ng, Lavanya Sankaran, and Sue Fox for their assistance in finding native speakers. I am indebted to my consultants, who patiently provided judgments for this study: Huang Zhipeng, Amanda Cheung, Youping Han, Jiang Dan, Lim Chey Cheng, Huifong Chen, and Dorothy Tan.
} 


\section{Introduction}

Chambers (2004: 28) describes vernacular universals as "a small number of phonological and grammatical processes [that] recur in vernaculars wherever they are spoken”. Such universals have been investigated fruitfully in monolingual varieties of English and recent efforts have aimed to incorporate contact varieties of English and cross-linguistic typology into this enterprise (Kortmann 2004). The search for 'angloversals' in bilingual postcolonial varieties is formalized in Kortmann and Szmrecsanyi's (2004; henceforth K\&S) typological survey of shared features in varieties of English.

Chambers observes of vernacular universals that

[t]heir ubiquity has one of two possible explanations. Either the features were diffused there by the founders of the dialect, or they developed there independently as natural structural linguistic developments... the diffusionist explanation is implausible because of geographical spread. It is also implausible linguistically, because these features occur not only in working-class and rural vernaculars but also in child language, pidgins, creoles and interlanguage varieties. Therefore, they appear to be natural outgrowths, so to speak, of the language faculty, that is, the species-specific bioprogram. (2004: 128)

Although Chambers envisions a unified paradigm for the study of sociolinguistic, acquisitional, diachronic and typological variation (2004: 130), the two explanations above are only appropriate for monolingual situations. Bilingual varieties of English will always involve a third potential explanation - the substrate. If we find a property recurring in two unrelated bilingual varieties, it is premature to draw a universalist conclusion unless substrate transfer has been ruled out. Even if the emergent feature is known to be typologically unmarked, it may simply be prevalent in and transferred from the substrates.

Similar methodological issues arise in K\&S's aggregation of English varieties to identify potential universals. In classifying the features of a given variety, they continue the practice in earlier work (Platt, Weber and Ho 1984; Williams 1987) of relying on broad presence or absence of the feature with little or no consideration of semantic or other conditioning. They acknowledge that this "bird's-eye view approach necessarily abstracts from many details and 
(partly necessary) qualifications in individual varieties" (2004: 1143). However, mere presence of a feature in two grammars cannot be taken to imply genuine typological similarity unless its grammatical conditioning is comparable (Poplack 2000; Tagliamonte 2002; Rickford 2006).

This article follows two basic criteria in extending the search for vernacular universals to bilingual cases: (i) ascertainment of a shared typological feature through quantitative examination of its conditioning, and (ii) elimination of substrate transfer explanations before making any appeals to universality. The analysis assesses three of K\&S's 'candidates for universals of new Englishes' — null past tense, over-extension of the progressive, and null copula. All three features are attested to some extent in both Indian English (IndE) and Singapore English (SgE). First, quantitative analysis reveals systematic patterns in the degree and conditioning of each feature in the two varieties. Second, substrates are found to play a central part in determining emergent systems: the one instance of closely parallel patterning in IndE and $\mathrm{SgE}$ (past tense omission) is accounted for by typological parallels in the substrates in that domain; differences in patterning (progressive and copula use) are accounted for by typological differences in the substrates. Despite the challenge of higher levels of variability in multilingual speech communities (Sankoff 2002: 640), this paper shows that close quantitative and substrate-sensitive analysis of apparent similarities across new varieties of English can reveal them to be typologically distinct in important ways.

\section{Universals in new Englishes}

The three features discussed in the present comparison of IndE and $\mathrm{SgE}$, listed in (1), are all among K\&S's 'candidates for universals of new Englishes' and are all described as shared across a number of regions, including Asian Englishes (2004: 1193):

(1) a. \#40: Zero past tense forms of regular verbs

b. \#21: Wider range of uses of the progressive

c. \#57: Deletion of be

K\&S list zero past tense as a feature typical of Caribbean, American, Pacific, and Asian varieties (2004: 1189; see also Jenkins 2003: 26), extension of the progressive to stative verbs 
as typical of Asian, American and African varieties (2004: 1189; see also Platt, Weber and Ho 1984: 72-3; Williams 1987: 172-3; Jenkins 2003: 26; Melchers and Shaw 2003: 22, 158; Trudgill and Hannah 2008: 107, 130, 137), and deletion of be as typical of Caribbean, Pacific, and Asian varieties (2004: 1193). Chambers (2004: 129) lists deletion of be as one of his top four candidates for English vernacular universals.

$\mathrm{K} \& \mathrm{~S}$ calculate the relative strength of representation of a feature across varieties by averaging its 'feature value' ( $1=$ pervasive, $0.5=$ infrequent, $0=$ absent) for all 46 varieties and 7 world regions examined. Thus, even if a feature is not found in all Asian varieties, if it is found in 3 out of a total 4 it receives a high 'feature ratio' score (0.75) for Asia and is included as 'typical' for the region. But what does this aggregation represent? If 3 of 4 Asian varieties have zero past marking because each of their substrates shares a narrower use for past morphology, then the high 'feature ratio' score does not reflect universality. Similarly, if 3 of 4 Asian varieties exhibit substantial deletion of be, but in each case a different grammatical context conditions deletion, based on substrate semantics, the high 'feature ratio' again does not reflect any sort of universality.

Filppula, Klemola and Paulasto (2009) pay closer attention to the question of whether universals or contact determine new systems, proposing a continuum between the two and suggesting that stative progressives may fall at the boundary between these two explanations. Van Rooy (2006) similarly offers a close comparison of progressive use in two varieties of English and identifies a Bantu source for divergence in the West African variety. Examining a different feature, article use, Sand (2004) pursues a quantitative comparison of several varieties, paying attention to the substrate in each case. She finds greater substrate influence in spoken than written genres, and, by ruling out substrate explanations elsewhere, argues convincingly that a number of semantic extensions in definite article use across varieties can be accounted for by "a common tendency to expand the rules of English article use in a certain way" based on universal semantic properties (2004: 295). In this paper, I follow these

\footnotetext{
${ }^{2}$ Sharma (2005) also finds a combination of substrate and universal effects in article use (K\&S's universal feature \#17): some substrate transfer arises from the specificity-marking article system of Hindi but universal discourse-driven tendencies intervene where the substrate does not supply an explicit form-meaning pairing.
} 
latter approaches in pursuing a quantitative exploration of semantic conditioning and substrate effects prior to concluding universality for any feature.

This approach helps to restrict broad universalist appeals to generalized L2 learning strategies as an explanation for surface similarities, as invoked by K\&S: “... it is now possible to give more substance to the notion of angloversals... Mair explicitly states that some of these angloversals may be the result of learning strategies of non-native speakers, in other words properties typical of L2 varieties" (2004: 1192). Properties that may appear to be "typical of L2 varieties' may in fact be parallel cases of transfer of typologically common features in the substrates, or may be differently conditioned in each variety. This is not to deny the potential for genuinely substrate-independent universals governing the cross-linguistic behaviour of tense-aspect systems (Bybee, Perkins and Pagliuca 1994) or copula systems (Stassen 1994), but rather to distinguish among degrees of similarity in new Englishes and types of explanations offered.

\section{Data}

IndE and $\mathrm{SgE}$ have markedly distinct linguistic ecologies in terms of languages in contact, their functional roles, degrees of nativization, official policies, and language ideologies. Within his Dynamic Model of the evolution of postcolonial Englishes, Schneider (2007: 153, 161) accurately characterizes IndE as currently at an earlier stage of indigenization (Phase 3 , 'Nativization') than $\mathrm{SgE}$ (Phase 4, 'Endonormative Stabilization'). In order to compare the syntactic properties of the two varieties in this study, I try to identify relatively comparable sets of conversational data from each speech community.

\subsection{Indian English}

The IndE data for this study come from 12 individuals, part of a larger bilingual corpus of IndE speakers. Only the subset of participants who show evidence of all three features are included here; it is important to note that many balanced bilingual speakers in the larger corpus do not show nonstandardness in copula omission and past tense use. The set of speakers in this study are non-English dominant and can be considered 'basilectal'. None of the participants had English-medium school education, although five had a limited amount of 
English-medium tertiary education and all had English as a school subject. They are all dominant in their first language but have regular (often work-related), daily use of English, often with other non-native speakers. All individuals lived in India until adulthood and acquired English through formal and informal modes in India; most are small shop owners, shop employees, or unemployed. The speech data consist of naturalistic, sociolinguistic interviews, lasting 0.5-2 hours, and ranging over topics such as work, leisure, cultural attitudes, and narratives of childhood and migration.

The primary substrate language for Northern IndE is Hindi, a language of wider communication across North India, but many speakers of IndE have at least one other additional native language. All participants are speakers of Hindi; two are additionally native speakers of Gujarati and three are native speakers of Punjabi. All three languages are identical in terms of copula use and tense-aspect parameters relevant to this discussion: they all require an overt copula in all predicate contexts (Masica 1991: 336); they all inflect for imperfective and for perfective with reflexes of the original Sanskrit participles; and they all mark progressive with an auxiliary verb comparable to Hindi rahna ('remain') (Masica 1991: 292302). I therefore use only Hindi as the representative substrate system in the analysis.

\subsection{Singapore English}

The SgE data for this study are drawn from secondary sources, in particular Ho and Platt (1993; henceforth H\&P), Platt (1979), and the ICE-Singapore corpus (with comparisons to the parallel corpus ICE-India). ${ }^{3} \mathrm{H} \& \mathrm{P}$ use a database of conversational interviews with 100 ethnically Chinese speakers of SgE, stratified into five educational levels. All participants in H\&P's study have completed some level of English-medium education unlike the IndE participants in my database. In order to ensure comparability I focus on the basilectal end of their data.

\footnotetext{
${ }^{3}$ Note that, in comparison to the ICE data, which dates from the 1990s, Ho and Platt's speakers date from the decades earlier, and are less likely to be native speakers of Singapore English or of Mandarin (Ansaldo 2004; Lim 2007). Given the historical background outlined in Section 3.2, Mandarin may therefore only be an important substrate for the newer ICE data, which is only used in Table 6. The attention to non-Mandarin substrates for $\mathrm{SgE}$ elsewhere in this paper is therefore relevant, given the nature of Ho and Platt's data (Lisa Lim, p.c.).
} 
As with IndE, $\mathrm{SgE}$ has a number of substrate inputs. Bao (2005) takes Mandarin as the dominant input due to its promotion in education since 1970; however, as $\mathrm{SgE}$ began to form much earlier than independence in 1965, Hokkien, Teochew, and Cantonese are widely seen as constituting the most important formative inputs (H\&P 1993: 27; Gupta 1994: 41; Ansaldo 2004; Lim 2007: 452; Yip and Matthews 2007: 236). Bazaar Malay is an additional major lingua franca, the Singaporean variety of which has been influenced by Hokkien (H\&P 1993: 9; Lim 2007: 453). Kuo (1980: 41, cited in Ng 2008) reports Singaporean home language statistics in 1957 as follows: Hokkien $(30 \%)>$ Teochew $(17.0 \%)>$ Cantonese $(15.1 \%)>$ Malay $(13.2 \%)>$ Mandarin $(0.1 \%){ }^{4}$

Mandarin has experienced a dramatic surge in use due to various forms of institutional promotion since independence. The Singapore Census of Population (2000) figures for reported home language in 1990 and 2000 indicate the scale of replacement of Chinese 'dialects' (39.6 in 1990; 23.8 in 2000) by Mandarin (23.7 in 1990; 35 in 2000). ${ }^{5}$ This increase certainly makes Mandarin a relevant substrate language as well, but it is then important to investigate the Singaporean variety of Mandarin, which, like Malay, has been affected by contact with other Chinese languages in Singapore. All of these substrate systems are examined in the analysis, using available published materials and native speaker consultations.

\footnotetext{
${ }^{4}$ Gupta (1994: 41) and Lim (2007: 454) warn against pure demographic inferences, however, noting that although Hokkien speakers may have dominated numerically in the mid-20 $0^{\text {th }}$ century, they may not have been the major Chinese input to SCE as the Cantonese adopted English more readily and may have played a central role in the resulting variety.

${ }^{5}$ The shift to Mandarin is even more evident across age groups. According to the Singapore Census of Population, in 2000 only $4.3 \%$ ethnically Chinese 5-14-year-olds spoke Chinese 'dialects' $(18.9 \%$ in 1990). By contrast, in $200071.8 \%$ of above-55-year-olds still speak Chinese 'dialects' $(87.7 \%$ in 1990). It is important to bear in mind that some proportion of these self-reported census data may be influenced by language ideologies rather than actual practice. Census figures remain fairly steady for Malay $(14.3 \% \rightarrow 14.1 \%)$, Tamil $(2.9 \% \rightarrow 3.2 \%)$, and English $(18.8 \% \rightarrow 23 \%)$.
} 
For the first two features examined (past and progressive morphology), we need to first consider the aspectual systems of the three language systems in question - the Hindi substrate for IndE, the Chinese substrate for $\mathrm{SgE}$, and English as the superstrate. These systems are presented in Table 1. (In all tables in this paper, parentheses in a cell indicate optionality or variation according to additional contextual factors.)

\section{@@ INSERT TABLE 1 HERE}

In the domain of past tense marking, there is a clear parallel between the two aspectprominent substrate languages, such that an overt marker is used with perfective (completive) reference. This is in contrast to the tense-prominent English system, in which the marking of past tense dominates any aspectual distinction.

In the domain of imperfective marking, however, the two substrate systems diverge. The only apparent similarity across all three imperfective systems is progressive marking. By contrast, Hindi requires overt marking of imperfectivity with - $t a$ whereas Mandarin has relatively restricted use of the marker -zhe within certain imperfective contexts. In fact, Yip and Rimmington (2004: 107) suggest that the treatment of -zhe as an aspectual marker at all is erroneous, and that it is more precisely a 'manner indicator': "zhe is suffixed to an action verb so that the resultant verbal phrase is used as a descriptive element in sentences to indicate 'manner' of existence', 'manner of movement', or 'accompanying manner'”. The form is by no means used across all imperfective contexts, as Hindi - $t a$ is, but rather is primarily reserved for temporary result states (Sun 2006). Its use is also conditioned by prosodic factors (Yip and Rimmington 2004: 127), another significant difference from Hindi -ta, which is strictly obligatory.

As noted, it can be problematic to use published descriptions of mainland Chinese Mandarin in the study of SgE. Table 2 provides the aspectual systems of Singapore Mandarin, Cantonese, Teochew, Hokkien, and Malay (consultants; Prentice 1990; H\&P 1993; Matthews and Yip 1994). The perfective pattern is consistent across Chinese languages and Malay. However, the restricted use of imperfective marking in Mandarin (as compared to Hindi) is, if 
anything, further reduced in other Chinese imperfective systems, including Singapore Mandarin; these differences are discussed further in Section 5.3.

\section{@@ INSERT TABLE 2 HERE}

We can conclude from Tables 1 and 2 that, although Indo-Aryan and Chinese languages can be classified together typologically as perfectivity-marking systems, they are typologically distinct in the domain of the imperfective. This makes them a useful comparative case study. If substrate languages in fact drive the emergent systems, we should expect to see the patterns in (2):

(2) a. SHARED FEATURE (-ed use): IndE and $\mathrm{SgE}$ will show a parallel transfer of perfective meaning to past tense morphology.

b. DIVERGENT FEATURE (-ing use): IndE and SgE will not show parallel behaviour in the imperfective.

i. IndE will exhibit greater use of -ing as a general marker of imperfectivity, due to obligatory overt imperfective marking in Indian substrates.

ii. SgE will exhibit less use of -ing as a general marker of imperfectivity, due to the limited range and optional use of overt imperfective marking in Singaporean substrates.

I first turn to a comparison of past tense morphology in IndE and $\mathrm{SgE}$ in Section 4, and then to a similar comparison of progressive morphology in IndE and $\mathrm{SgE}$ in Section 5. In Section 6 I briefly review the final example of copula absence to support the analysis.

\section{Past tense omission (K\&S \#40)}

Perfective sentences denote completed or temporally bounded situations, also called events, while imperfective sentences denote unbounded, ongoing situations (Comrie 1976). Clausal perfectivity can be conveyed simply by lexical aspect, i.e. telic verbs, which contain an endpoint (e.g. complete, build, dismantle, drown) or by additional grammatical aspect markers, i.e. morphology that imposes a bounded viewpoint on a predicate such as perfective 
morphology (e.g. Mandarin le) or perfectivizing adverbials (e.g. in two minutes, all of a sudden).

The emphasis in research on past tense morphology in learning situations has been on lexical aspect (see Andersen and Shirai 1996). However, Sharma and Deo (2008) argue that IndE past omission is not a universal lexical effect, but rather involves overt marking of sentential perfectivity modelled precisely on the speakers' Indo-Aryan L1s. ${ }^{6}$ Table 3 shows that basilectal IndE speakers clearly ascribe perfective meaning to English past morphology (modelled on perfectivity-marking in their native Indo-Aryan), and tend to avoid overt past marking in imperfective sentences. Although I treat habituals semantically as derived states in my data, they are grouped with progressives and separated from lexical statives in Table 3, following H\&P's methodology, to ensure comparability of Tables 3 and 4.

\section{@@ INSERT TABLE 3 HERE}

Fortunately, H\&P (1993: 81-3, 151) explore the semantic contexts of past omission in SgE in much the same way. A close examination of their method for classifying predicates reveals that their analysis goes beyond lexical aspect as well and incorporates most core elements of clausal aspect. They follow Bickerton (1981) in using the term 'punctual' "in a very broad sense" to include predicates bearing the features [+completive] and [+telic]; this corresponds to the standard term 'perfective'. Similarly, their category 'stative non-punctual' includes predicates bearing the feature [+stative] and their category 'non-stative non-punctuals' includes predicates bearing the features [+duration], [+activity], and [+habitual]; these correspond to standard categories of 'imperfective'. Their results are therefore directly comparable to the IndE data.

\section{@@ INSERT TABLE 4 HERE}

\footnotetext{
${ }^{6}$ Drawing on theories of aspect in the semantics literature, Sharma and Deo (2008) critique the excessive focus on lexical aspect alone in second language acquisition studies, particularly when the L1 in question is sensitive to clausal perfectivity. They offer various types of evidence to support the view that clausal perfectivity conditions past tense use in IndE, including tense choice in cases of misaligned lexical and clausal aspect and fine conditioning of past tense marking by perfective and imperfective types. Their analysis examines the data in Table 3 and Table 5 in more detail.
} 
Table 4 shows a strikingly similar pattern to the IndE distribution, whereby past tense is used significantly more with perfective predicates than with imperfective predicates. ${ }^{7}$ Figure 1 shows how similar the IndE and SgE distributions are for past tense use.

\section{@@ INSERT FIGURE 1 HERE}

As predicted in (2a), we see a direct replication in both IndE and $\mathrm{SgE}$ of perfectivity marking in the substrate systems. It is possible that a universal preference for marking perfectivity is emerging; however, having examined the substrates, we certainly cannot conclude this. Only further comparisons to English varieties with non-perfectivity-marking substrates can verify this. At present, the IndE and SgE may be seen as a straightforward instance of strict transfer (Lefebvre 1998; Bao 2005), as in (3), whereby the semantic component of a form-meaning pairing in the L1 is re-attached to an L2 form.

$$
\begin{aligned}
& \text { (i) Hindi: }[\text { PERF }-a] \quad \rightarrow \quad \text { IndE: [PERF -ed] } \\
& \text { (ii) Chinese: [PERF le }] \rightarrow \text { SgE: [PERF -ed] }
\end{aligned}
$$

One difference that does emerge between IndE and $\mathrm{SgE}$ perfectivity marking is also directly explicable by substrate differences. $\mathrm{SgE}$ has grammaticalized already as an additional perfective marker (Bao 1995, 2005); this usage follows formal analogy with analytic Chinese and Malay forms le and sudah. Hindi does not have isolated forms of this kind and consequently IndE has not grammaticalized adverbs for aspectual functions.

\section{Over-extension of the progressive $(\mathrm{K} \& S \# 21)$}

The predictions in (2b) anticipate divergence between IndE and $\mathrm{SgE}$ in the domain of imperfective marking. Indian speakers of English may experience substrate pressure to mark both perfectivity and imperfectivity with explicit markers (the latter is only implicitly signalled by the lack of past marking seen earlier in Table 3). As -ing is the only marker in the

\footnotetext{
${ }^{7}$ A chi-square test of significance could not be presented for the $\mathrm{SgE}$ data in Table 4 as the original study only provides a composite $\mathrm{N}$ value.
} 
imperfective domain in English, it is likely to be the immediate candidate for this function. $\mathrm{SgE}$ speakers, by contrast, are not expected to encounter this pressure.

\subsection{Use of progressive -ing in IndE}

The imperfective categories examined here are progressive, stative, delimited habituals, and non-delimited habituals. I distinguish between two types of habituals because of their distinct behaviour in standard varieties of English with respect to the use of progressive -ing. In general, a sentence with a habitual predicate describes a generalization over episodes rather than reporting a particular episode (a habitual operator thus transforms any eventuality type into a state); the sub-type of delimited habituals asserts or presupposes a time-bound on the habit described, whereas the sub-type of non-delimited habituals does not. Since the form -ing in Standard English primarily imposes a dynamic, in-progress reading, the form can be used with delimited habituals due to their time-bound property, e.g. I'm eating meat these days, but not with non-delimited habituals, which are not tied to a particular timespan, e.g. *I'm eating meat.

Thus, of the four imperfective categories only progressive and delimited habitual environments productively license the use of the progressive form in native Standard English varieties. A few further uses of the progressive (e.g. with temporary states I'm wanting to move back) are discussed later, but for the most part the use of the progressive is non-standard with non-delimited habituals, statives, and perfectives, e.g. *I'm eating meat, *I'm knowing the answer, *I was moving to Miami in 1998.

\section{@@INSERT TABLE 5}

Table 5 presents the proportion of all progressive -ing forms across the four imperfective contexts in the IndE data. ${ }^{8}$ It is clear that a robust over-extension to non-delimited habituals

\footnotetext{
${ }^{8}$ Note that this approach is the reverse of the approach taken for past tense, where all past contexts were examined for use of the past form. This is because for past tense we are interested in restrictions on the distribution of the form, i.e. omission, whereas for progressive we are interested in extensions in the distribution of the form. Furthermore, the optionality of the progressive in many standard contexts renders an examination of all potential sites of use relatively intractable.
} 
and statives, i.e. to the remaining imperfective categories, has taken place in IndE. ${ }^{9}$ Examples from the data showing systematic -ing use with non-delimited habitual reference are given in (4) and with stative reference in (5).

(4) Over-extension to non-delimited habituals ${ }^{10}$

a. I have got a driver. My son driving his own car.

[IA:d103]

b. Generally only dry-cleaning clothes are coming.

c. There's no Indian crowd [in Rochester] and it's snowing.

d. Every week I'm calling [my parents].

[RS:c171]

(5) Over-extension to statives

a. Some people are thinking it's a bad job.

[MM:d138]

b. For sociology they were asking me for $80 \% \ldots$ But I was only having $70 \%$. [DD:d108]

c. Japanese patients... would not be knowing English at all.

d. Then what they'll feel is like, we are knowing each other.

\subsection{Use of progressive -ing in $\mathrm{SgE}$}

Unfortunately, H\&P do not provide quantitative data on semantic contexts of -ing use, but some indication of $\mathrm{SgE}$ usage can be gleaned from corpus data and from qualitative comments in $\mathrm{H} \& \mathrm{P}$.

In the $\mathrm{SgE}$ corpus ICE-Singapore, very slight over-extension of -ing does occur, but in quantitative terms it is negligible as compared to the corresponding IndE uses of -ing in the parallel corpus, ICE-India. As a brief illustration, I present all $\mathrm{BE}+\mathrm{V}$ uses of having and knowing in ICE-Singapore and ICE-India in Table $6 .{ }^{11}$ The difference between IndE and SgE

\footnotetext{
${ }^{9}$ The few perfective verbs that occur with the progressive are come, start, and begin; although telic, these verbs are also associated with null marking of past. This may suggest that inceptives and ingressives present a semantic clash with perfective interpretations for these speakers.

${ }^{10}$ Non-delimited status was established from the discourse context by, for instance, the absence of explicit or implied temporal delimiters such as these days.

${ }^{11} 11$ of the 24 uses of knowing by IndE users included modals (e.g. You must be knowing this all history, don't you?; As you may be knowing...). These were coded as non-standard based on eight native British English consultants' grammaticality ratings, all of which were lower than ratings given
} 
is dramatic, but it is still noteworthy that two of the four uses of having in $\mathrm{SgE}$ are stative. Standard and non-standard examples of having from each corpus are given in (6) and (7) respectively.

\section{@@ INSERT TABLE6 HERE}

(6) Standard examples of having:

a. Experiential: Having my hols now and am having a great time. [ICE-SIN: w1b-010:545]

b. Experiential: I'm having a real tough time categorizing the sex you know.

[ ICE-IND: S1a-048:1131]

c. Future: This afternoon we are having high tea with the Rustomjees. [ICE-IND: W2f-016:238]

d. Habitual: So each and every party is uh having a bandh [strike] everyday.

[ICE-IND: S1a-057:174]

(7) Non-standard examples of having:

a. Maybe that's why I'm having a crush on him.

[ICE-SIN: w1b-010.txt:342]

b. I'm having a talk [speech] next week.

[ICE-SIN: w1b-010.txt:342]

c. We are having different beaches.

d. He therefore uh doesn't say that the deceased was also having O group. [ICE-IND: S2a-067:514]

SgE shows no evidence of recasting -ing as a general imperfective marker as IndE does, but (7a) and (7b) indicate slight variation in use. Further support for the view that SgE shows slight variation, but not on the scale of IndE, comes from H\&P (1993: 64-6). They too find a number of instances of over-extension of the progressive to habitual and lexically stative contexts in their data. Some examples from their data are listed in (8). ${ }^{12}$ However, they emphasize that "in general, the state-process distinction holds for Singaporean Chinese learners of English" (1993: 189).

for the non-progressive equivalents. Variation did occur in the degree of ungrammaticality for these consultants, indicating increasing permissiveness with stative progressives in standard native varieties. ${ }^{12}$ An important difference between IndE and $\mathrm{SgE}$ is evident in (8), namely the absence of be in the construction; H\&P (1993: 65) observe that this is based on a direct analogy with the lack of be in Chinese systems. Indo-Aryan languages require a be auxiliary with imperfective markers, and so this difference can also be ascribed to a difference in the substrates. 
P13.18. $\quad$ Like sometime dey having dinner.

A18.5. You having excess (cash) in your box.

P5.1. I living here.

P20.37. Most of de time I speaking English down there.

P10.4. $\quad$ I use(d) to go in and flying in and out.

T3.12. Den he carrying an umbrella.

\subsection{Discussion}

Unlike perfectivity-marking with -ed, which followed a parallel pattern in IndE and SgE, imperfectivity-marking with -ing is very different in the two varieties. In both we find some variation with respect to the semantic range of -ing, but in IndE this leads to a systemic shift to marking all imperfective categories with -ing, while in SgE such a shift does not happen.

This finding immediately rules out certain types of explanations. First, an account based on general lexical-semantic levelling in contact situations is unlikely, e.g.: "South Asian English often uses the progressive... with stative verbs, so that $I$ am knowing is possible. This can be regarded as neutralization of the stative/dynamic contrast and is perhaps parallel to the neutralization of the count/noncount distinction that produces luggages" (Melchers and Shaw 2003: 141). A universalist interpretation of such levelling cannot explain the discrepancy between IndE and SgE usage. It is also unclear why IndE would neutralize a distinction that is maintained in the L1, Hindi.

At the other end of explanatory models, a strict substrate reading of stative/dynamic levelling such as Bickerton's for IndE is also ruled out: "Native speakers of Hindi frequently make mistakes such as *I am liking it... Hindi speakers apparently commit [this mistake] because in Hindi imperfective marking can be used with statives" (Bickerton 1984:155-6). This view anticipates that $\mathrm{SgE}$ should also over-generalize the English progressive, as $\mathrm{SgE}$ substrates also have stativity markers such as $-z h e$. Furthermore, as with Melchers and Shaw's account, it does not explain why Hindi speakers level at all, instead of simply equating their own distinctive progressive form rahna with English -ing.

The puzzle is therefore this: If the substrates and the superstrate all make a parallel distinction between progressive contexts (rahna in Hindi, zai and related forms in Chinese, -ing in 
English) and other imperfective contexts (-ta in Hindi, -zhe and related forms in Chinese, default absence of marking in English), then why is a single form adopted for both functions in one variety (IndE) at all, and why not in the other $(\mathrm{SgE})$ ?

In this analysis, I focus on two factors: (i) the extended range of uses of -ing in English and (ii) relative robustness of imperfective forms in the substrate. The first of these is shared by both varieties (giving rise to the variation we see in both $\mathrm{SgE}$ and $\mathrm{IndE}$ ) and the second is distinctive in each variety (giving rise to a shift only in IndE) Together, these factors suggest an explanation based on substrate-superstrate interaction. I first consider IndE according to these two factors, and then $\mathrm{SgE}$.

The first step in analyzing the IndE progressive is to critique the view, in Table 1, that all varieties involved have comparable progressive forms. In order to do this, I move from the core set of imperfective contexts in Table 1 to the expanded set of constructions in Table 7. Table 7 does not offer a semantically driven grouping of construction types; it simply serves to highlight certain differences in the distribution of imperfective morphology in the three systems in question.

\section{@@ INSERT TABLE 7 HERE}

The first important observation in Table 7 is the wide range of constructions involving Standard English progressive -ing as compared to the Hindi progressive rahna. Comrie (1976: 25 ) notes this unusually wide range and describes the Standard English progressive as "a kind of imperfective". Certain statives occur with -ing in English, for instance, when a change in degree is involved or when the state is temporary, e.g. I'm living there but plan to move; I'm thinking we should sell it. The form -ing is also licensed with classes of predicates such as perception, posture, and location; other languages frequently focus on the result state or change-of-state properties of such classes (as in Hindi, see Table 7). The English gerund further extends the uses of -ing, and the form can even escape progressive meaning altogether in non-finite constructions, instead signalling simultaneity, e.g. Knowing that Maya was in town, I planned a party. (Comrie 1976: 36-9).

By contrast, the Hindi progressive performs a much stricter function (although it does share the peripheral functions of future and of preliminary stage interpretation of achievements). In 
a contact situation, the English superstrate will always present learners with this complex distribution of -ing; if this distribution comes up against a narrow progressive form in the L1, this is likely to always instigate some variation caused by the L1-L2 progressive boundary mismatch and a resulting search for the correct semantic scope of -ing. Here we see potential for a genuine 'angloversal' deriving from a peculiarity of the superstrate.

The second detail to recognize in Tables 1 and 7 is that Hindi is a strict imperfectivitymarking system, such that all finite clauses must be marked as either perfective or imperfective. The form - $t a$ is never optional in habitual and stative contexts. This means that IndE speakers have a pervasive substrate pressure to mark imperfectivity overtly.

The superstrate and substrate therefore both contribute to the following procedure. In their search for an overt imperfective marker, driven by the substrate, IndE speakers encounter -ing as a prominent candidate. Due to its extended range, the form -ing appears to equally map to rahna and -ta and IndE speakers interpret it as a global imperfectivity marker.

An intriguing effect is that, although IndE results from an interaction between two grammars, the resulting system is typologically distinct from both input systems. It can be classified with other single imperfectivity-marker systems such as French, as shown in Table 8.

\section{@@ INSERT TABLE 8 HERE}

How does this procedure play out in SgE? Table 7 showed that Hindi has a narrow progressive form which differs substantially from the broad scope of English -ing, and also that Hindi has a robust, obligatory imperfective marker. Table 9 provides a similar range of constructions along with the relevant substrate morphology for $\mathrm{SgE}$.

\section{@@ INSERT TABLE 9 HERE}

First, we can see that the mismatch between the scope of English and Hindi progressives is repeated in Table 9; in fact, the mismatch is even more dramatic as future and preliminary 
stage uses of zai/tja/do/gan are excluded. ${ }^{13}$ Table 7 and Table 9 thus share an L1-L2 mismatch that gives rise to parallel variation in the 'boundary search' for -ing. H\&P (1993: 189) also cite the "extended use of -ing constructions in the established varieties of English" as an influence on over-extension of -ing in $\mathrm{SgE}$.

By contrast, in the area of imperfective marking, although we find overt markers such as zhe/zyu/do in Chinese, their use is dramatically different from Hindi -ta. They are strictly markers of continuous states and are not used in many imperfective constructions such as habituals, simultaneity, and persistence. There is also extensive optionality in the use of these forms according to prosodic and word order factors. Some Singapore Mandarin-speaking consultants for this paper reported total optionality in the use of -zhe, most likely due to contact with Hokkien, Cantonese, and Teochew. The forms -zhe/zyu/do are thus semantically highly restricted and frequently omitted in Singaporean usage. ${ }^{14}$ Convergence across substrates in the Singaporean case may reinforce the lack of pressure to mark imperfectivity (Ansaldo 2004).

On the one hand, then, there is a resemblance to the IndE situation in the L1-L2 mismatch in the scope of the progressive form, caused by the superstrate. On the other hand, there is an absence of any strong Chinese substrate pressure to mark imperfectivity overtly, despite the presence of some imperfective markers. The first of these factors causes some variation due to

\footnotetext{
${ }^{13}$ In Standard Malay, sedang is also not used for future reference or simultaneity and is "much less frequent than English progressive" (Svalberg and Chuchu 1998: 39). Bazaar Malay is missing from Table 9 due to lack of access to native speakers, but the column would be comparable to Hokkien as Malay does not have stativity markers. Teochew also has only one primarily progressive marker $d o$, which shows some uses in zhe contexts, such as with posture and location (this slight difference in the dynamic/stative boundary is also true for the use of Cantonese gan).

${ }^{14}$ Published grammars claim that-zhe is required with stative verbs such as love and with verbs of posture and activity verbs signalling states. My Singapore Mandarin consultants treat all of these as optional contexts, and so optionality is indicated for all Singapore Mandarin -zhe use in Table 9. H\&P and Bao (2005) both rely primarily or exclusively on Standard Mandarin descriptions (e.g. Li and Thompson 1981; Smith 1991), and assume a 'universal Chinese grammar' (Chao 1968: 13). The present discussion shows the importance of other Chinese languages and the Singaporean variety of Mandarin in further reducing any substrate pressure to mark imperfectivity in $\mathrm{SgE}$.
} 
a 'boundary search', but the second reduces the pressure among SgE speakers to seek an overt marker for imperfectivity, and the variety eventually approximates Standard English usage.

This substrate-superstrate interaction can be schematized as in (9). The transfer of imperfective meaning to -ing - robustly in IndE and negligibly in $\mathrm{SgE}$ - is triggered by the general encroachment of English -ing into non-progressive territory. A substrate element remains crucial, however: the robustness of Hindi - ta as an imperfective marker gives rise to an expanded -ing system; by contrast, the optional Chinese -zhe/zyu/do result state markers have little, if any, effect on how the SgE system stabilizes.

(9) a. English

Hindi

Hindi

[ALL OTHER IMPERF

[NARROW PROG

rahna]

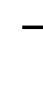

$-t a]$

b. English

[WIDE PROG -ing]

Chinese

Chinese
[NARROW PROG

[WIDE PROG -ing]

$\begin{array}{lr}\text { [NARROW PROG } & z a i] \\ \text { [OPTIONAL STATIVE } & -z h e]\end{array}$


use of a copula... I was not able to collect any data from ICE-SIN which would show statives (love, believe, know) being used in the $\mathrm{V}$-ing form... The stative imperfective is not found in Singapore English. (2005: 249-50)

Both the claim that the progressive in Chinese and in English are parallel and the claim that ICE-Singapore does not have instances of stative uses of -ing are complicated by the present discussion. Bao is correct in suggesting that $\mathrm{SgE}$ broadly conforms to Standard English behaviour, but the discussion in this section has identified empirical evidence of microvariation in $\mathrm{SgE}$ caused by the non-equivalence of English and Chinese progressives; this does not stabilize partly due to the influence of non-Mandarin substrate systems, excluded from Bao's analysis.

One remaining mystery is why the contact situation in $(9 b)$ does not lead to under-use of the progressive in $\mathrm{SgE}$ due to the highly restricted domain of zai. The sources cited suggest broadly standard rather than restricted use of -ing (although Table 6 does suggest the possibility of quantitative under-use). This can be accounted for by a version of the Subset Principle (Berwick 1985), whereby if a learner is starting from a grammar that is a subset of the target grammar, they can expand straightforwardly to the target based on positive evidence in the input. Thus, a SgE speaker may restrict English -ing to zai contexts at first, but would then encounter clear evidence for its wider use. By contrast, an IndE grammar that uses -ing as an imperfective marker already generates all standard -ing contexts and would therefore require explicit negative evidence to be restricted.

\section{Copula absence $(K \& S \# 57)$}

In this final analysis section, I briefly summarize results from an examination of copula omission to support the present findings. Sharma and Rickford (2009) compare copula omission in African-American Vernacular English (AAVE), creoles, new Englishes, and child/adult learner English. This feature has been widely assumed to be shared across creoles and learner varieties (Winford 1998: 114; McWhorter 2000: 420; Wolfram 2000: 54;

Chambers 2004: 129), but Sharma and Rickford conclude that the mere fact of variable copula omission in these varieties belies underlying divergence in the grammatical conditioning of these systems. 
Following many studies of the deletion of be (see Rickford 1998 for a summary), I use the term 'copula' here to include strictly copular be (with non-verbal predicates, e.g. nominal: She is my sister; adjectival: She is funny; locative: She is in the hall) and auxiliary be (with verbal predicates, e.g. V+ing: She is hiding; future gonna: She is gonna pay). Figure 2 draws together rates of copula absence according to each predicate type, where possible, with a focus on Indian and Chinese substrates, and Table 10 provides the systems of copula use in each relevant substrate language. ${ }^{15}$

\section{@@ INSERT FIGURE 2 HERE}

\section{@@ INSERT TABLE 10 HERE}

It should be clear from Figure 2 that although each variety has some degree of copula absence, the underlying system differs substantially in SgE, IndE, and South African IndE (SAIE). To a great extent, the substrate system in each case can account for relative frequencies of copula absence.

$\mathrm{SgE}$ (Malay L1) has the highest absolute rates out of the four bilingual varieties in Figure 2, and Table 10 shows that Malay does not use a copula in any of the predicate contexts.

SgE (Chinese L1) has lower rates of copula absence than SgE (Malay L1) but higher than IndE, and, as Table 10 indicates, the relevant substrates have an intermediate system of copula

\footnotetext{
${ }^{15}$ Notes for Figure 2 and Table 10: The high Loc values in SgE (Malay) in Figure 2 are based on a low total $\mathrm{N}$ value of 5 . As individual speaker rates cannot be extracted for some of the datasets in Figure 2, standard deviation measures could not be included. All of these data sets are discussed more extensively in Sharma and Rickford (2009). Sources of data in Figure 2: Malay L1 SgE (Platt 1979); Chinese L1 SgE (basilectal data, H\&P 1993: 48); IndE (Sharma and Rickford 2009); SAIE (Mesthrie 1992: 158); AAVE (Labov 1972: 86); Barbadian Creole (Rickford 1992: 192). Sources of data in Table 10: Malay (Platt 1979), Tamil (Pillai 1992: 15; Schiffman 1999: 141), Chinese (Platt 1979), Indo-Aryan (Masica 1991: 336).
} 
use as well. The two highest contexts for omission in $\mathrm{SgE}$ (Chinese L1) are the two contexts in which Chinese systems omit the copula. ${ }^{16}$

Basilectal South African IndE (Dravidian L1) shows yet another distribution, mimicking the two highest contexts for copula absence in Tamil (see Table 10).

IndE (Indo-Aryan L1) shows the lowest rates overall of copula absence, and indeed, as Table 10 shows, the substrate languages involved have an obligatory copula with all predicate types. Copula absence is not robust in IndE: 'mesolectal' or balanced English-Hindi bilinguals do not have copula omission at all, and each individual IndE speaker in the composite data in Figure 2 was found to have a different ordering of contexts, also suggesting no strong underlying system.

In contrast to these four New English varieties, the examples of an AAVE variety and a creole variety in Figure 2 are striking in exhibiting a genuinely similar distribution. A coarse grouping of all six systems in Figure 2, merely based on the fact of copula absence, obscures the genuine similarity between AAVE and creoles as well as the strong evidence for specific L1 transfer in the other four systems (see Sharma and Rickford 2009 for further discussion and statistical measures).

As with past omission and progressive over-extension, copula omission occurs in both IndE and $\mathrm{SgE}$ but quantitative analysis reveals a distinct patterning according to grammatical context in the two varieties, driven by substrate differences.

\footnotetext{
${ }^{16}$ Ansaldo (2004, this volume) argues that copula absence across SgE substrates has a 'ganging-up' effect on copula absence in the emergent variety. This is certainly true of the effect of Malay and Chinese, although in Figure 2 we can still see traces of marginal divergences in Malay and Chinese in the corresponding sub-varieties of SgE. Ho and Platt's data are relatively old and it is possible that SgE sub-varieties have now focussed towards a new, more unified omission pattern (Lisa Lim, p.c.).
} 


\section{Conclusions}

This paper has argued that, in the search for vernacular universals, we cannot simply treat varieties that exhibit presence of a particular trait as identical, particularly where bilingual varieties of English are concerned. Surface similarities across new Englishes can be skin deep, diverging dramatically upon closer examination, due to substrate systems or substratesuperstrate interaction. If we genuinely aim to "identify those features which are the result of language contact, irrespective of the languages involved" (Sand 2004: 281), then it is inadequate to define a feature as broadly as 'zero past tense forms of regular verbs' (K\&S \#40), 'wider range of uses of the progressive' (K\&S \#21), or 'deletion of be' (K\&S \#57). The degree and distribution of a given feature must be understood in relation to the substrate before any universal claims can be made regarding "processes [that] recur in vernaculars wherever they are spoken..." (Chambers 2004: 28).

The quantitative comparison of two features - K\&S \#40 (past tense use) and K\&S \#21 (progressive use) - showed that although both features can be found in IndE and SgE, their patterning is genuinely similar in one case and substantially different in the other. The use of past tense marking to indicate perfectivity was strikingly parallel in IndE and $\mathrm{SgE}$, and the substrate systems were found to be parallel as well. The use of progressive -ing to indicate imperfectivity was strikingly different in IndE and $\mathrm{SgE}$, and the substrate systems were found to be different as well. Finally, K\&S \#57 (copula omission) was also found to occur in both IndE and $\mathrm{SgE}$, as well as in other new Englishes, but in each case the grammatical conditioning is heavily influenced by the substrate language, such that some varieties do not retain copula absence as a feature of mesolectal speech (IndE) whereas others do (SgE).

Certainly repeated patterns may indeed derive from universal principles. Walker (2007) offers syntactic and processing explanations for clear quantitative parallels in variable agreement across native varieties of English, likely to be repeated regardless of the contact situation. However, for bilingual varieties of English it is imperative to first investigate and eliminate substrate explanations. The parallel assignment of perfective meaning to past tense morphology in IndE and $\mathrm{SgE}$ found in this study, for instance, is a genuinely comparable pattern yet it is not necessarily a universal. A simple substrate explanation accounts for the pattern, and only further comparison to varieties with distinct substrates can determine whether a substrate or unmarked explanation is appropriate. 
Similarly, even though we know that typologically progressive markers regularly grammaticalize into general imperfective markers (Bybee, Perkins, and Pagliuca 1994: 140), $\mathrm{SgE}$ did not show the same robust over-extension of -ing as IndE did, thus ruling out a markedness explanation and supporting a substrate explanation. The curious additional complexity here is that, although it arose out of the contact between the grammars of Hindi and English, the innovative treatment of -ing as a global imperfective marker by IndE speakers results in a system that is typologically distinct from both input systems.

Although this article cannot establish whether universals may additionally reinforce selected patterns found in $\mathrm{SgE}$ and IndE, it has shown that substrate-superstrate interactions can go a long way towards explaining emergent systems in postcolonial varieties of English, and that highly abstracted aggregations of varieties in the search for universals may obscure these sources of change. 


\section{References}

Andersen, Roger, and Yasuhiro Shirai. 1996. "The primacy of aspect in first and second language acquisition: The pidgin-creole connection”. In William C. Ritchie and Tej Bhatia, eds. Handbook of Second Language Acquisition. London: Academic Press, 52770.

Ansaldo, Umberto. 2004. "The evolution of Singapore English: Finding the matrix". In Lisa Lim, ed. Singapore English: A Grammatical Description. Varieties of English Around the World G33. Amsterdam, Philadelphia: John Benjamins, 127-49.

Ansaldo, Umberto. 2009 (this volume). "The Asian typology of English: Theoretical and methodological considerations”. English World-Wide 30(2).

Bao, Zhiming. 1995. “Already in Singapore English”. World Englishes 14(2): 181-8.

Bao, Zhiming. 2005. "The aspectual system of Singapore English and the systemic substratist explanation". Journal of Linguistics 41: 237-67.

Berwick, Robert. 1985. The Acquisition of Syntactic Knowledge. Cambridge, MA: MIT Press.

Bickerton, Derek. 1981. Roots of Language. Ann Arbor: Karoma.

Bickerton, Derek. 1984. “The Language Bioprogram Hypothesis”. The Behavioral and Brain Sciences 7: 173-221.

Bybee, Joan, Revere Perkins, and William Pagliuca. 1994. The Evolution of Grammar: Tense, Aspect, and Modality in the Languages of the World. Chicago: University of Chicago Press.

Chambers, Jack. 2004. "Dynamic typology and vernacular universals”. In Bernd Kortmann, ed. Dialectology meets Typology. Berlin, New York: Mouton de Gruyter, 127-45.

Chao, Yuen Ren. 1968. A Grammar of Spoken Chinese. Berkeley: University of California Press.

Comrie, Bernard. 1976. Aspect. Cambridge: Cambridge University Press.

Filppula, Markku, Juhani Klemola, and Heli Paulasto. 2009 (forthcoming). "Digging for roots: universals and contacts in regional varieties of English”. In Markku Filppula, Juhani Klemola, and Heli Paulasto, eds. Vernacular Universals and Language Contacts: Evidence from Varieties of English and Beyond. London: Routledge.

Gupta, Anthea Fraser. 1994. The Step-Tongue: Children's English in Singapore. Cleveland, UK: Multilingual Matters.

Jenkins, Jennifer. 2003. World Englishes. London: Routledge. 
Ho, Mian Lian, and John Platt. 1993. Dynamics of a Contact Continuum. Oxford: Oxford University Press.

Kortmann, Bernd, ed. 2004. Dialectology Meets Typology: Dialect Grammar from a CrossLinguistic Perspective. Berlin: Mouton de Gruyter.

Kortmann, Bernd, and Benedikt Szmrecsanyi. 2004. "Global synopsis - morphological and syntactic variation in English". In Bernd Kortmann, Kate Burridge, Raj Mesthrie and Edgar Schneider, eds. A Handbook of Varieties of English, Vol. 2: Morphology and Syntax. Berlin, New York: Mouton de Gruyter, 1122-82.

Kuo, Eddie C.Y. 1980. “The sociolinguistic situation in Singapore: Unity in diversity”. In Evangelos A. Afendras and Eddie C. Y. Kuo, eds. Language and Society in Singapore. Singapore: Singapore University Press, 39-62.

Labov, William. 1972. Language in the Inner City: Studies in the Black English Vernacular. Philadelphia, PA: University of Pennsylvania Press.

Lefebvre, Claire. 1998. Creole Genesis and the Acquisition of Grammar: The Case of Haitian Creole. Cambridge: Cambridge University Press.

Li, Charles N., and Sandra Thompson. 1981. Mandarin Chinese: A Functional Reference Grammar. Berkeley: University of California Press.

Lim, Lisa. 2007. "Mergers and acquisitions: On the ages and origins of Singapore English particles." World Englishes 26(4): 446-73.

Masica, Colin P. 1991. The Indo-Aryan Languages. Cambridge: Cambridge University Press.

Matthews, Stephen, and Virginia Yip. 1994. Cantonese: A Comprehensive Grammar. London: Routledge.

McWhorter, John. 2000. "Strange bedfellows: Recovering the origins of Black English". Diachronica XVII(2): 389-432.

Melchers, Gunnel, and Philip Shaw. 2003. World Englishes: An Introduction. London: Arnold.

Mesthrie, Rajend. 1992. English in Language Shift. Cambridge: Cambridge University Press. Ng, E-Ching. 2008. "English meets Malay meets Chinese: Colloquial Singaporean English". Presented at the Workshop on interdisciplinary approaches to transfer, crosslinguistic influence and contact-induced change, UWE Bristol, July 2008.

Pillai, N. Nadaraja. 1992. A Syntactic Study of Tamil Verbs. Mysore: Central Institute of Indian Languages.

Platt, John. 1979. "Variation and implicational relationships: Copula realization in Singapore English”. General Linguistics 19(1):1-14. 
Platt, John, Heidi Weber, and Ho Mian Lian. 1984. The New Englishes. London: Routledge. Poplack, Shana, ed. 2000. The English History of African American English. Oxford: Blackwell.

Prentice, D.J. 1990. "Malay (Indonesian and Malaysian)”. In Bernard Comrie, ed. The World's Major Languages. Oxford: Oxford University Press, 913-35.

Rickford, John R. 1992. "The creole residue in Barbados”. In Joan H. Hall, Nick Doane, and Dick Ringler, eds. Old English and New: Studies in Honor of Frederic G. Cassidy. New York, London: Garland, 183-201.

Rickford, John R. 1998. "The Creole origins of African-American Vernacular English: Evidence from copula absence”. In Salikoko Mufwene, John R. Rickford, Guy Bailey, and John Baugh, eds. African-American English: Structure, History, Use. London: Routledge, 154-200.

Rickford, John R. 2006. "Down for the count? The Creole Origins Hypothesis of AAVE at the hands of the Ottawa Circle, and their supporters". Journal of Pidgin and Creole Languages 21: 97-155.

Sand, Andrea. 2004. "Shared morpho-syntactic features in contact varieties of English: Article use". World Englishes 23(2): 281-98.

Sankoff, Gillian. 2002. "Linguistic outcomes of language contact”. In Jack Chambers, Peter Trudgill, and Natalie Schilling-Estes, eds. The Handbook of Language Variation and Change. Oxford: Blackwell, 638-68.

Schiffman, Harold. 1999. A Reference Grammar of Spoken Tamil. Cambridge: Cambridge University Press.

Schneider, Edgar. 2007. Postcolonial English: Varieties Around the World. Cambridge: Cambridge University Press.

Sharma, Devyani. 2005. "Language transfer and discourse universals in Indian English article use". Studies in Second Language Acquisition 27(4): 535-66.

Sharma, Devyani, and Ashwini Deo. 2008. "The semantics of tense-aspect restructuring in contact situations". Queen Mary University of London and Yale University. Ms.

Sharma, Devyani, and John Rickford. 2009 (in press). "AAVE/Creole copula absence: A critique of the Imperfect Learning Hypothesis". Journal of Pidgin and Creole Languages 24:1.

Singapore Census of Population. 2000. "Literacy and language". Singapore Department of Statistics, Census of Population Office. Accessed from www.singstat.gov.sg, September 15, 2008. 
Smith, Carlota S. 1991. The Parameter of Aspect. Dordrecht: Kluwer-Reidel.

Stassen, Leon. 1994. "Typology versus mythology: The case of the zero-copula". Nordic Journal of Linguistics 17: 105-26.

Sun, Chaofen. 2006. Chinese: A Linguistic Introduction. Cambridge: Cambridge University Press.

Svalberg, Agneta, and H.F. Chuchu. 1998. "Are English and Malay worlds apart? Typological distance and the learning of tense and aspect concepts". International Journal of Applied Linguistics 8(1): 27-60.

Tagliamonte, Sali. 2002. "Comparative sociolinguistics". In Jack Chambers, Peter Trudgill and Natalie Schilling-Estes, eds. Handbook of Language Variation and Change. Malden, MA, Oxford: Blackwell, 729-63.

Trudgill, Peter, and Jean Hannah. 2008. International English: A Guide to Varieties of Standard English, 5th edition. Oxford: Oxford University Press.

Van Rooy, Bertus. 2006. "The extension of the progressive aspect in Black South African English”. World Englishes 25(1): 37-64.

Walker, James. 2007. “There's bears back there: Plural existentials and vernacular universals in (Quebec) English”. English World-Wide 27(2): 147-66.

Williams, Jessica. 1987. "Non-native varieties of English: A special case of language acquisition". English World-Wide 8(2): 161-99.

Winford, Donald. 1998. "On the origins of African American Vernacular English: A creolist perspective. Part II: Linguistic features". Diachronica 15(1): 99-155.

Wolfram, Walt. 2000. "Issues in reconstructing Earlier African American English”. World Englishes 19(1): 39-58.

Yip, Po-Ching, and Don Rimmington. 2004. Chinese: A Comprehensive Grammar. London: Routledge.

Yip, Virginia, and Stephen Matthews. 2007. The Bilingual Child: Early Development and Language Contact. Cambridge: Cambridge University Press. 
Author's address:

Devyani Sharma

Linguistics Department

Queen Mary University of London

Mile End Road

London E1 4NS

Email: d.sharma@qmul.ac.uk 
Table 1. Key aspect distinctions in Hindi, Mandarin, and English

\begin{tabular}{|c|c|c|c|c|c|}
\hline & & & Hindi & Mandarin & English \\
\hline \multirow{2}{*}{ 苾 } & & Perfective & $-(y) a$ & le & - \\
\hline & (ii) & Neutral & - & - & -ed \\
\hline \multirow{3}{*}{ 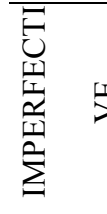 } & (i) & Progressive & rahna & zai & -ing \\
\hline & (ii) & Non-progressive & $-\mathrm{ta}$ & (-zhe) & - \\
\hline & (iii) & Habitual & $-\mathrm{ta}$ & - & - \\
\hline
\end{tabular}


Table 2. Comparison of Singaporean substrate tense-aspect marking

\begin{tabular}{|c|c|c|c|c|c|c|c|c|}
\hline & & & & $\begin{array}{l}\text { Singapore } \\
\text { Mandarin }\end{array}$ & Cantonese & Teochew & Hokkien & Malay \\
\hline 氡 & 立 & $\begin{array}{l}\text { (i) } \\
\text { (ii) }\end{array}$ & $\begin{array}{l}\text { Perfective } \\
\text { Neutral }\end{array}$ & le & tso & lio & liau & sudah \\
\hline 空 & $\stackrel{1}{>}$ & $\begin{array}{l}\text { (i) } \\
\text { (ii) } \\
\text { (iii) }\end{array}$ & $\begin{array}{l}\text { Progressive } \\
\text { Non-progressive } \\
\text { Habitual }\end{array}$ & $\begin{array}{c}\text { zai } \\
\text { (-zhe) }\end{array}$ & $\begin{array}{l}\text { gan } \\
\text { (zyu) } \\
\text { (hoi) }\end{array}$ & $\begin{array}{l}\text { do } \\
\text { (do) }\end{array}$ & tja & sedang \\
\hline
\end{tabular}


Table 3. Past tense marking according to clausal aspect $(\mathrm{N}=702)$

\begin{tabular}{|c|c|c|c|}
\hline & & \% OVERT PAST & $\mathbf{N}$ \\
\hline \multirow{3}{*}{ 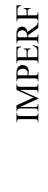 } & Habitual, progressive & 29.5 & 132 \\
\hline & Lexical stative & 44.2 & 224 \\
\hline & PERFECTIVE & 76.6 & 346 \\
\hline
\end{tabular}

$\chi^{2}(2 \mathrm{dof})=109.96, \mathrm{p} \leq 0.001$ 
Table 4. Past tense marking according to sentential aspect $(\mathrm{N}=8725)$

\begin{tabular}{|c|c|c|}
\hline & & $\%$ OVERT PAST \\
\hline \multirow{3}{*}{ 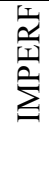 } & Habitual, progressive & 14.7 \\
\hline & Lexical stative & 36.9 \\
\hline & PERFECTIVE & 56.2 \\
\hline
\end{tabular}


Table 5. Functions of progressive forms $(\mathrm{N}=339)$

\begin{tabular}{|c|c|c|c|}
\hline & & \% OF FUNCTIONS & $\overline{\mathbf{N}}$ \\
\hline \multirow{5}{*}{ 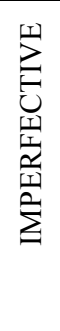 } & Delimited habitual & 33.1 & 112 \\
\hline & Non-delimited habitual & 30.8 & 104 \\
\hline & Progressive & 18.4 & 63 \\
\hline & Stative & 14.8 & 50 \\
\hline & PERFECTIVE & 2.9 & 10 \\
\hline
\end{tabular}


Table 6. Use of main verb having and knowing in ICE-India and ICE-Singapore

\begin{tabular}{lcccc}
\hline \hline & \multicolumn{2}{c}{ ICE-India } & \multicolumn{2}{c}{ ICE-Singapore } \\
& standard & non-standard & standard & non-standard \\
\hline BE + HAVING & 47 & 141 & 4 & 2 \\
BE + KNOWING & 0 & 24 & 0 & 0 \\
\hline \hline
\end{tabular}


Table 7. Use of imperfective forms in Hindi, Standard English, Indian English

\begin{tabular}{|c|c|c|c|c|}
\hline Type & Example & English & Hindi & $\begin{array}{l}\text { Indian } \\
\text { English }\end{array}$ \\
\hline Progressive & He is WRITING a letter. & -ing & rahna & -ing \\
\hline Preliminary stage & He's ARRIVING now. & -ing & rahna & -ing \\
\hline Future & She's LEAVING tomorrow. & -ing & rahna & $-i n g$ \\
\hline Weather & It's RAINING. & -ing & rahna & $-i n g$ \\
\hline Delimited habitual & She's DRIVING these days. & - / -ing & $-t a /$ rahna & -ing \\
\hline Adverb over time & FLYING all day, the bird got tired. & -ing & $-t a$ & $-i n g$ \\
\hline $\begin{array}{l}\text { Adverb } \\
\text { (simultaneity) }\end{array}$ & He walked towards me SMILING. & -ing & $-t a$ & $-i n g$ \\
\hline Persistent activity & The wind kept BLOWING. & -ing & $-t a$ & $-i n g$ \\
\hline State & You LOVE music. & - & $-t a$ & $-i n g$ \\
\hline Habitual & I DRIVE. & - & $-t a$ & $-i n g$ \\
\hline Dress & She is WEARING boots. & -ing & $-a($ perf) & $-i n g$ \\
\hline Posture & He is STANDING outside. & -ing & -a (perf) & $-i n g$ \\
\hline Location & A letter was LYING there. & -ing & $-a($ perf $)$ & $-i n g$ \\
\hline Temporary state & He is HOLDING the book. & -ing & $-a($ perf $)$ & $-i n g$ \\
\hline Nonfinite & They like SWIMMING. & -ing & -na (inf) & -ing \\
\hline
\end{tabular}

Note: Progressive forms are marked in bold, and other imperfective forms in italics. 
Table 8. Imperfective marking in Hindi, Standard English, Indian English, and French

\begin{tabular}{lcccc}
\hline & Hindi & $\begin{array}{c}\text { Standard } \\
\text { English }\end{array}$ & Indian English & $\begin{array}{c}\text { French } \\
\text { (PAST) }\end{array}$ \\
\hline Progressive & rahna & - ing & - ing & IMPARFAIT \\
Stative & - ta & $(-$ ing $)$ & $-i n g$ & IMPARFAIT \\
Habitual & - ta & $(-i n g)$ & $-i n g$ & IMPARFAIT \\
Possession & hona (be) & have & $-i n g$ & IMPARFAIT \\
\hline \hline
\end{tabular}


Table 9. Use of imperfective forms in English and Chinese languages

\begin{tabular}{|c|c|c|c|c|c|}
\hline Example & $\begin{array}{l}\text { Standard } \\
\text { English } \\
\text { (and SgE) }\end{array}$ & $\begin{array}{l}\text { Singapore } \\
\text { Mandarin }\end{array}$ & Hokkien & Teochew & Cantonese \\
\hline He is WRITING a letter. & -ing & zai & tja & do & gan \\
\hline He's ARRIVING now. & -ing & - & - & - & - \\
\hline She's LEAVING tomorrow. & -ing & - & - & - & - \\
\hline It's RAINING. & -ing & - & - & - & (gan) \\
\hline She's DRIVING these days. & - / -ing & - & - & - & - \\
\hline He walked towards me & -ing & $(-z h e)$ & - & (do) & $(z y u)$ \\
\hline \multicolumn{6}{|l|}{ SMILING. } \\
\hline The wind kept BLOwING. & -ing & - & - & - & - \\
\hline You LOVE music. & - & $(-z h e)$ & - & - & - \\
\hline I DRIVE. & - & - & - & - & - \\
\hline The car is in the garage. & - & $(-z h e)$ & - & (do) & $z y u$ \\
\hline She is WEARING boots. & -ing & - & - & - & $z y u$ \\
\hline He is STANDING outside. & -ing & $(-z h e)$ & - & (do) & (gan) \\
\hline A letter was LYING there. & -ing & $(-z h e)$ & - & (do) & (gan) \\
\hline He is HOLDING the book. & -ing & $(-z h e)$ & - & (do) & $z y u$ \\
\hline They like sWIMMING. & -ing & - & - & - & - \\
\hline
\end{tabular}

Note: Progressive forms are marked in bold, and other imperfective forms in italics. 
Table 10. Copula used in equivalent L1 construction?

\begin{tabular}{lcccc}
\hline & NOM & LOC & ADJ & VERB \\
\hline Malay & no & no & no & no \\
Cantonese/ & $(\checkmark)$ & $\checkmark$ & no & no \\
Mandarin & & & & \\
Tamil & no & $\checkmark$ & $(\checkmark)$ & no \\
Hindi & $\checkmark$ & $\checkmark$ & $\checkmark$ & $\checkmark$ \\
\hline \hline
\end{tabular}




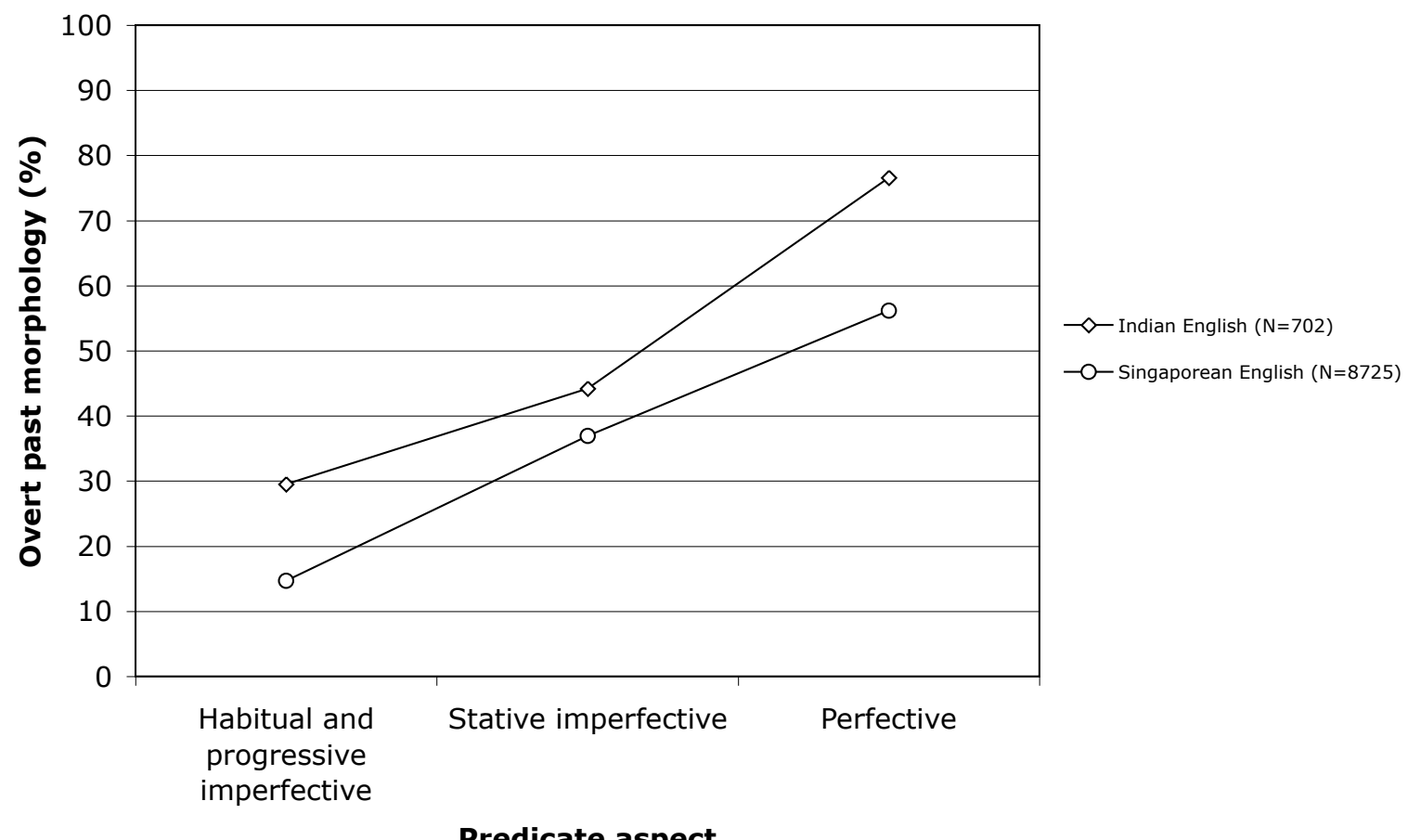

Figure 1. Past tense use according to clausal aspect in IndE and $\mathrm{SgE}$ 


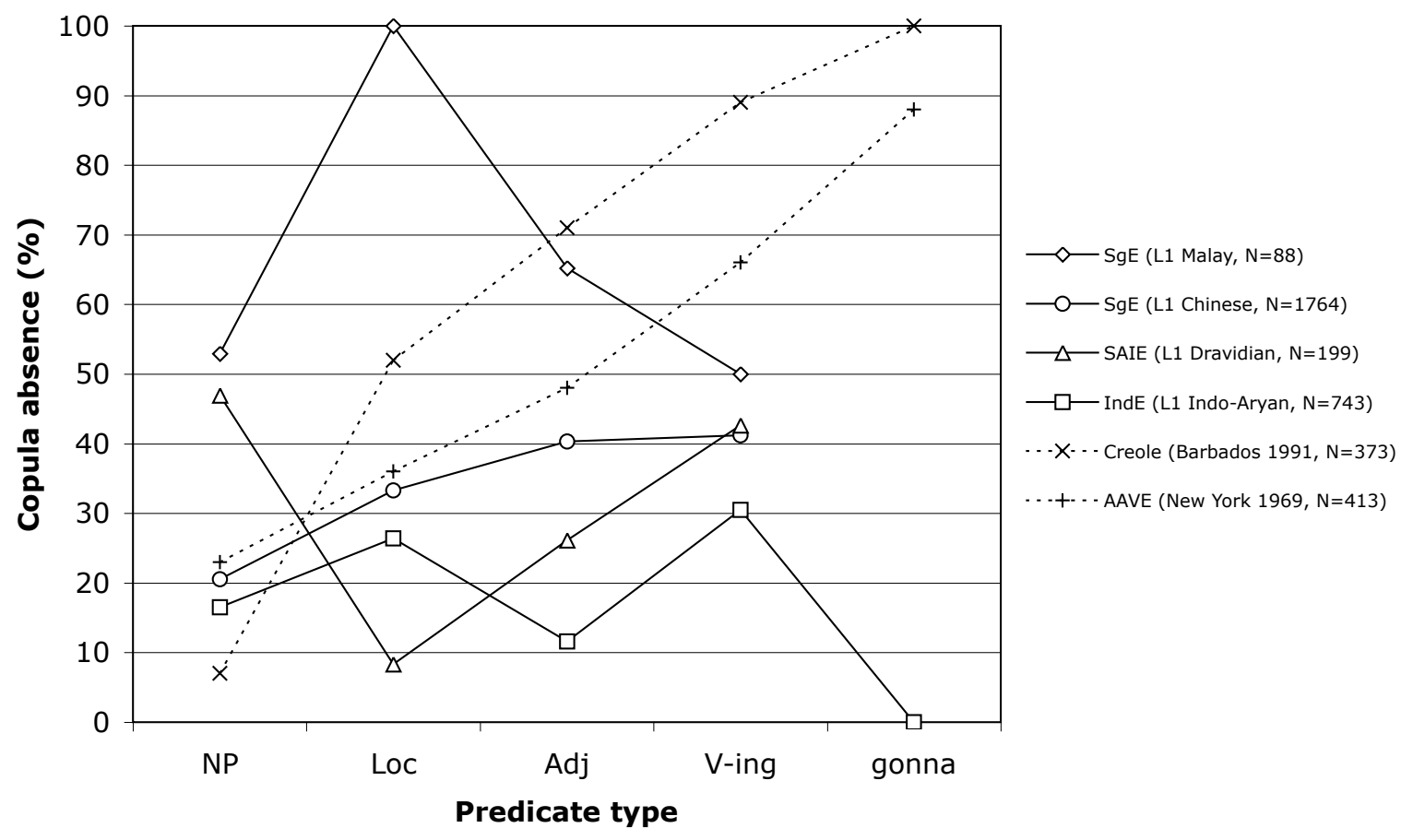

Figure 2. Copula absence by predicate type (based on Sharma and Rickford 2009) 